\title{
Electroencephalographic changes during selective attention
}

\author{
Nisha Ghimire1, Bishnu Hari Paudel ${ }^{2}$, Rita Khadka ${ }^{3}$, Paras Nath Singh" ${ }^{4}$ Asim Das ${ }^{5}$ \\ ${ }^{1}$ Assistant Professor, Department of Basic and Clinical Physiology, B. P. Koirala Institute of Health Sciences, Dharan, Nepal, ${ }^{2}$ Professor, \\ Department of Basic and Clinical Physiology, B. P. Koirala Institute of Health Sciences, Dharan, Nepal, ${ }^{3}$ Associate Professor, Department \\ of Basic and Clinical Physiology, B. P. Koirala Institute of Health Sciences, Dharan, Nepal, ${ }^{4}$ Professor, Past: B.P. Koirala Institute of Health \\ Sciences, Dharan, Nepal, Current: Professor, All India Institute of medical Sciences, Patna, Bihar, India, ${ }^{5}$ Professor, Past: B.P. Koirala Institute \\ of Health Sciences, Dharan, Nepal, Current: Professor, E.S.I Medical College, India
}

\section{A B S TRA C T}

Background: Though many studies are conducted during attention process, it is still not clear how brain deals with attention. So we conducted a study to find out the electroencephalographic changes during selective attention. Methods: Thirty healthy right handed male students aged $23.1 \pm 2.8$ yrs were asked to read congruent (red printed in red ink) and incongruent (red printed in blue ink) words printed in cards. EEG was recorded for ninety seconds during baseline (eye open) and reading of both cards. EEG epoch was analyzed by fast fourier transformation. Friedman test was used to compare EEG power spectra among baseline, congruent and incongruent reading followed by Wilcoxon's Sign Rank Test. Data were expressed as median with inter-quartile range. Results: Compared to congruent test during incongruent test there was selective increment of theta power at Fz [36.04 (28.30-46.19) vs. 47.89 (31.65-48.1)], $\mathrm{Cz}[36.13(27.20-46.41)$ vs. $45.66(37.15-49.4)]$ and $C 4[25.11(19.14-30.06)$ vs. $30.16(21.43-33.8)]$ sites but it decreased at F7 [17.88 (14.49-20.93) vs. 11.31(8.96-15.975)] and F8 [19.23 (13.61-25.79) vs. 13.95 (10.40-16.67) sites. Also during incongruent card reading, alpha1 power significantly decreased in F8 [3.39(2.63-4.63) to $2.75(1.93-4.7)]$ and alpha 2 power significantly decreased in P3 6.84 [(4.88-10.46) to 5.74 (4.78-19.95)] sites. Conclusion: During selective attention, theta gets synchronized at fronto-central regions and alpha2 desynchronized at parietal regions. The theta and alpha1 at inferior frontal regions were also desynchronized in selective attention.

Key words: Selective attention, Theta, Frontal and central regions, Alpha 2 parietal region
Access this article online Website:

http://nepjol.info/index.php/AJMS

DOI: 10.3126/ajms.v6i2.11122

\section{INTRODUCTION}

Attention remains a major area of investigation within education, Psychology and neuroscience. CT, MRI, PET and EEG studies suggest activation of different brain areas when subjects perform different activities. EEG can be used as an effective tool for CNS arousal. ${ }^{1}$ EEG is divided into delta, theta, alpha and beta bands. Studies have shown changes in these frequency bands during attention.

EEG studies have found associations of theta-band, mainly frontal midline theta with the performance of working memory, emotional states, attention processes and also during relief from anxiety. ${ }^{2}$ Frontal midline theta has been shown to increase in high load task than low load task. ${ }^{3}$ Event related desynchronization of alpha waves suggest cortical arousal during attention. ${ }^{4}$ The alpha band has been considered to be an idling rhythmbut now it is proposed that increased alpha power may index the active inhibition of non-task relevant cortical areas during memory and attention tasks. ${ }^{5}$ The post-movement beta synchronization is also interpreted as a correlate of idling motor cortex neurons. ${ }^{6}$ Beta band is strongest from frontal lobes and is produced by visual stimuli and mental activity. ${ }^{7}$ Though studies are conducted to see the activities of different EEG bands during attention, it is still not clear how the change in EEG waves explains attention process. Selective attention is also a type of

Address for Correspondence:

Nisha Ghimire, Asistant Professor, B.P. Koirala Institute of Health Sciences,Dharan, Nepal.

E-mail: nishaghi3@gmail.com, nishaghi@yahoo.com; Telephone no.9819374270

๑) Copyright AJMS 
attention which emphasizes the efficient encoding of relevant target in spite of potential overwhelming quantity of sensory information. ${ }^{8}$ EEG tracings during selective attention also showed theta oscillations in the anterior cingulate cortex which increased with task difficulty ${ }^{9}$ but it is still not clear how brain deals with selective attention. So, we conducted the study to observe the EEG changes during selective attention compared to normal reading. So as to fulfil our objectives, we used a classical version of stroop card which has congruent card [naming of a colour printed in a colour denoted by the name (red printed in red ink)] and incongruent card [naming of a colour printed in a colour not denoted by the name (red printed in blue ink).

\section{MATERIALS AND METHOD}

This cross-sectional experimental study was conducted on randomly selected thirty healthy right handed male undergraduate and post graduate students $(n=30)$ of age group $23.1 \pm 2.8$ years with normal eye sight having normal color vision. Subjects with history of medical illness, physical disability, seizure disorder, neurological disorder, color blindness, psychoactive substance abuse/misuse and any drug intake that might affect EEG were excluded from the study. After detailed medical history, physical examination subjects were familiarized with the laboratory setup and conditions. Digital EEG machine, its accessories (OLV-1100/1200 series, Nihon Kohden) and Classical Stroop cards (congruent and incongruent $)^{10}$ were used in the study. Procedure was explained to them followed by obtaining the consent. Ten sample words from both control and experimental cards were given to read to make the subject acquaint with procedure. Subjects were asked to sit down and feel comfortable in a chair for the placement of electrodes and subsequent procedure. Electrodes were placed according to International 10-20 system. Electrooculographic activity was recorded from electrodes located in the center of the supraorbital ridge above each eye, referenced to an electrode at the outer canthus of each eye. Once they were in place, the impedance of each electrode was checked for impedance to be less than 5 kilo-ohms. Time constant was maintained at $0.3 \mathrm{~Hz}$ and high cutoff frequency was maintained at $70 \mathrm{~Hz}$.

\section{Recording procedure}

Before the beginning of experiment, subjects were asked to relax for 5 minutes. Baseline EEG was taken in eyes open condition for ninety seconds. During eye open condition the subjects were asked to stare at blank wall in front. Card was held in front of subject at about $50 \mathrm{~cm}$ from eye level. Then on the signal " $1,2,3$ go" the subjects were instructed to read aloud congruent words. Simultaneously, EEG record was taken for ninety seconds. After reading of control card was finished, subjects were asked to relax for 5 minutes. After relaxing, baseline eye open EEG record was taken. Then subjects were asked to read experimental incongruent card. All the procedures adopted were similar except the colors of the print of the words were to be read. (red word printed in blue color had to be called blue). All events (beginning and end) of each reading activity were marked on EEG to enable EEG epoch selection.

\section{Data analysis}

EEG waveforms were reduced and analyzed using "Focus" software (version 1.1). Initially, the records were visually inspected on the computer to check for eye blinks, detectable eye movements, and body movement artifacts during the procedure. After visual inspection, artifact free $3 \mathrm{sec}$ epochs were selected at $20^{\text {th }}, 40^{\text {th }}, 60^{\text {th }}$ and $80^{\text {th }} \mathrm{sec}$ from eye open, control and experimental condition. Thereafter Fast Fourier Transformation was performed on these data for decomposition of EEG waveform into sine wave components in terms of respective frequencies. The ethical clearance was received from the institutional ethical review board BPKIHS.

\section{Statistical analysis}

Median with interquartile range was obtained for theta alpha1, aplha2 and beta waves in all brain areas. Since our data was not normally distributed and it included more than two matched groups, first Friedman's analysis was used to compare power spectrum in different brain areas within same group. Afterwards Wilcoxon's Sign Rank Test was used to compare power spectrum of the bands between 1. eye open-congruent, 2. eyeopen -incongruent and 3. congruent- incongruent for only significant ones found from Friedman's test Stroop Test.

\section{RESULTS}

Compared with baseline, during both congruent and incongruent tests, theta power increased at $\mathrm{Fz}, \mathrm{C} 4, \mathrm{Cz}$ and $\mathrm{O} 1, \mathrm{~F} 7$ and $\mathrm{F} 8$ regions however increase in theta in $\mathrm{Fz}, \mathrm{C} 4, \mathrm{Cz}$, was even more significant during incongruent stroop test. Like in these regions power of theta also increased at F7 and F8 sites during both tests compared to baseline but in contrary theta power in these sites was significantly less during incongruent test than congruent test (Table 1, Figure 2, Figure 3, Figure 4). Similarly Alpha1 activity also increased in $\mathrm{F} 7$ and $\mathrm{F} 8$ regions during both tests compared to baseline but decreased activity at F8 during incongruent test was only in F8 region (Table 2, Figure 2, Figure 3, Figure 4). 
Alpha 2 decreased at P4 and Pz sites during both tests compared to baseline. The decrement of alpha2 at these sites was significantly more during incongruent test. In addition there was significant decrease in alpha2 power at P3 region during incongruent test.

Beta was found to be increased at almost all sites during both tests except $\mathrm{Fz}, \mathrm{Pz} \mathrm{Cz}, \mathrm{P} 4$ and P3 regions. But significant differences between two tests were not found. (Table 3, Figure 2, Figure 3, Figure 4).

\section{DISCUSSION}

Stroop test is a test of selective attention. Though some studies suggested frontal lobe acting as anterior

\begin{tabular}{|c|c|c|c|c|c|c|c|c|c|c|}
\hline \multirow{2}{*}{$\begin{array}{l}\text { Electrodes } \\
\text { sites } \\
\text { Theta }\end{array}$} & \multicolumn{2}{|c|}{$\begin{array}{c}\text { Eye open, }(\mathrm{n}=30) \\
\text { Power spectrum }\left(\mu v^{2}\right) \\
\text { Median (interquartile range) }\end{array}$} & \multicolumn{2}{|c|}{$\begin{array}{c}\text { Congruent test, }(n=30) \\
\text { Power spectrum }\left(\mu v^{2}\right) \\
\text { Median (interquartile range) }\end{array}$} & \multicolumn{2}{|c|}{$\begin{array}{l}\text { Incongruent test, }(n=30) \\
\text { Power spectrum }\left(\mu v^{2}\right) \\
\text { Median (interquartile range) }\end{array}$} & \multirow[t]{2}{*}{ p1 } & \multirow[t]{2}{*}{ p2 } & \multirow[t]{2}{*}{ p3 } & \multirow[t]{2}{*}{ p4 } \\
\hline & & & & & & & & & & \\
\hline $\mathrm{Fz}$ & 24.60 & $(21.13-38.26)$ & 36.04 & $(28.30-46.19)$ & 47.89 & $(31.65-48.1)$ & 0.001 & 0.001 & 0.001 & 0.015 \\
\hline $\mathrm{Cz}$ & 27.69 & $(20.34-38.73)$ & 36.13 & $(27.20-46.41)$ & 45.66 & $(37.15-49.4)$ & 0.001 & 0.010 & 0.001 & 0.014 \\
\hline $\mathrm{C} 4$ & 16.54 & (14.52-28.22) & 25.11 & (19.14-30.06) & 30.16 & $(21.43-33.8)$ & 0.001 & 0.018 & 0.001 & 0.007 \\
\hline F8 & 4.74 & $(3.73-7.42)$ & 19.23 & (13.61-25.79) & 13.95 & $(10.40-16.67)$ & 0.001 & 0.001 & 0.001 & 0.001 \\
\hline $\mathrm{F} 7$ & 6.30 & $(4.89-7.51)$ & 17.88 & (14.49-20.93) & 11.31 & (8.96-15.975) & 0.001 & 0.001 & 0.001 & 0.001 \\
\hline 01 & 13.84 & $(11.51-18.91)$ & 22.16 & $(17.61-32.70)$ & 21.09 & $(17.28-28.1)$ & 0.001 & 0.001 & 0.001 & Ns \\
\hline
\end{tabular}

\begin{tabular}{|c|c|c|c|c|c|c|c|c|c|c|}
\hline \multirow{2}{*}{$\begin{array}{l}\begin{array}{l}\text { Electrodes } \\
\text { sites }\end{array} \\
\text { Alpha1 }\end{array}$} & \multicolumn{2}{|c|}{$\begin{array}{c}\text { Eye open, }(\mathrm{n}=30) \\
\text { Power spectrum }\left(\mu \mathrm{v}^{2}\right) \\
\text { Median (interquartile range) }\end{array}$} & \multicolumn{2}{|c|}{$\begin{array}{l}\text { Congruent test, }(n=30) \\
\text { Power spectrum }\left(\mu v^{2}\right) \\
\text { Median (interquartile range }\end{array}$} & \multicolumn{2}{|c|}{$\begin{array}{l}\text { Incongruent test, }(n=30) \\
\text { Power spectrum }\left(\mu \mathrm{v}^{2}\right) \\
\text { Median (interquartile range) }\end{array}$} & \multirow[t]{2}{*}{ p1 } & \multirow[t]{2}{*}{ p2 } & \multirow[t]{2}{*}{ p3 } & \multirow[t]{2}{*}{ p4 } \\
\hline & & & & & & & & & & \\
\hline $\mathrm{Pz}$ & 10.58 & $(6.98-18.28)$ & 8.49 & $(6.39-13.92)$ & 9.58 & $(6.2875-19.525)$ & 0.015 & 0.010 & Ns & Ns \\
\hline Fp2 & 5.26 & $(4.31-7.33)$ & 6.30 & $(5.27-10.74)$ & 6.93 & $(5.10625-11.75)$ & 0.03 & 0.028 & 0.02 & Ns \\
\hline F8 & 1.63 & $(1.23-2.04)$ & 3.39 & $(2.63-4.63)$ & 2.75 & $(1.93-4.7)$ & 0.000 & 0.001 & 0.002 & 0.039 \\
\hline P4 & 9.34 & $(5.95-21.09)$ & 6.83 & $(4.99-10.26)$ & 7.48 & $(4.9625-16.7)$ & 0.045 & 0.05 & $\mathrm{Ns}$ & $\mathrm{Ns}$ \\
\hline $\mathrm{F} 7$ & 2.05 & $(1.35-2.69)$ & 3.32 & $(2.48-4.88)$ & 2.96 & $(2.16-5.1)$ & 0.03 & 0.002 & 0.010 & Ns \\
\hline \multicolumn{11}{|l|}{ Alpha2 } \\
\hline $\mathrm{Pz}$ & 10.83 & $(7.51-24.98)$ & 7.68 & $(6.44-11.51)$ & 6.45 & $(4.98-23.125)$ & 0.016 & 0.006 & 0.001 & Ns \\
\hline F8 & 1.44 & $(0.87-2.43)$ & 2.55 & $(2.01-3.44)$ & 2.20 & $(1.4375-3.525)$ & 0.01 & 0.002 & 0.018 & Ns \\
\hline P4 & 9.93 & $(5.95-19.48)$ & 7.43 & $(4.49-11.50)$ & 5.94 & $(4.53-20.275)$ & 0.005 & 0.009 & 0.001 & Ns \\
\hline $\mathrm{F} 7$ & 1.50 & $(1.01-2.18)$ & 2.28 & $(1.73-2.64)$ & 2.28 & $(1.83-3.225)$ & 0.02 & 0.003 & 0.012 & Ns \\
\hline P3 & 8.28 & $(4.64-19.96)$ & 6.84 & $(4.88-10.46)$ & 5.74 & $(4.78-19.95)$ & 0.016 & Ns & 0.002 & 0.006 \\
\hline
\end{tabular}

$n=$ No. of subjects, $p<.05=$ Significant. Overall comparison ( $p 1)$ by Friedman's test and multiple comparisons between eye open and congruent test ( $p 2)$, eye open and incongruent test $\left(\mathrm{p}_{3}\right)$ and congruent and incongruent test $\left(\mathrm{p}_{4}\right)$ by Wilcoxon's Sign rank test

\begin{tabular}{|c|c|c|c|c|c|c|c|c|c|c|}
\hline \multirow{2}{*}{$\begin{array}{l}\text { Electrodes } \\
\text { sites } \\
\text { Beta }\end{array}$} & \multicolumn{2}{|c|}{$\begin{array}{c}\text { Eye open, }(n=30) \\
\text { Power spectrum }\left(\mu v^{2}\right) \\
\text { Median (interquartile range) }\end{array}$} & \multicolumn{2}{|c|}{$\begin{array}{c}\text { Congruent test, }(n=30) \\
\text { Power spectrum }\left(\mu v^{2}\right) \\
\text { Median (interquartile range) }\end{array}$} & \multicolumn{2}{|c|}{$\begin{array}{l}\text { Incongruent test, }(n=30) \\
\text { Power spectrum }\left(\mu v^{2}\right) \\
\text { Median (interquartile range) }\end{array}$} & \multirow[t]{2}{*}{$\mathrm{p} 1$} & \multirow[t]{2}{*}{ p2 } & \multirow[t]{2}{*}{ p3 } & \multirow[t]{2}{*}{ p4 } \\
\hline & & & & & & & & & & \\
\hline $\mathrm{Fp} 2$ & 15.26 & $(12.44-30.84)$ & 25.75 & $(19.86-36.85)$ & 26.45 & $(18.45-34.37)$ & 0.001 & 0.001 & 0.001 & Ns \\
\hline F8 & 6.10 & $(4.52-9.18)$ & 12.09 & $(10.56-15.95)$ & 11.15 & $(8.07-14.70)$ & 0.001 & 0.001 & 0.001 & Ns \\
\hline $\mathrm{C} 4$ & 16.73 & $(13.11-32.38)$ & 25.06 & $(18.10-30.63)$ & 23.19 & (15.71-34.12) & 0.001 & 0.004 & 0.010 & Ns \\
\hline $\mathrm{T} 4$ & 16.71 & $(9.90-36.36)$ & 43.75 & $(21.80-68.98)$ & 33.45 & $(14.79-48.42)$ & 0.001 & 0.001 & 0.001 & Ns \\
\hline T6 & 12.64 & (9.66-20.17) & 27.31 & $(16.56-44.86)$ & 21.94 & $(16.75-42.07)$ & 0.001 & 0.001 & 0.001 & Ns \\
\hline Fp1 & 16.54 & $(11.41-26.79)$ & 24.95 & $(18.86-33.55)$ & 27.39 & $(20.95-31.47)$ & 0.001 & 0.001 & 0.001 & Ns \\
\hline $\mathrm{F} 7$ & 6.31 & $(4.44-8.32)$ & 9.70 & $(7.68-11.24)$ & 9.25 & $(6.66-10.85)$ & 0.001 & 0.001 & 0.001 & Ns \\
\hline F3 & 13.80 & $(12.04-23.24)$ & 18.89 & $(14.71-26.19)$ & 21.29 & $(14.61-27.82)$ & 0.001 & 0.001 & 0.001 & Ns \\
\hline C3 & 15.49 & $(11.50-24.27)$ & 19.56 & $(15.13-27.95)$ & 20.03 & $(12.71-29.77)$ & 0.002 & 0.027 & 0.003 & Ns \\
\hline T3 & 15.30 & $(5.84-33.18)$ & 37.88 & $(15.24-59.18)$ & 26.21 & $(13.55-53.07)$ & 0.001 & 0.001 & 0.001 & Ns \\
\hline T5 & 12.46 & $(7.90-21.54)$ & 20.40 & $(14.93-28.33)$ & 18.28 & (13.91-31.07) & 0.001 & 0.001 & 0.001 & Ns \\
\hline 01 & 17.03 & $(12.78-26.56)$ & 23.36 & $(16.96-30.02)$ & 22.56 & $(18.16-30.12)$ & 0.001 & 0.002 & 0.006 & Ns \\
\hline
\end{tabular}

$\mathrm{n}=$ No. of subjects, $\mathrm{p}<.05=$ Significant Overall comparison ( $\mathrm{p} 1$ ) by Friedman's test and multiple comparisons between eye open and congruent test ( $\mathrm{p} 2)$, eye open and incongruent test $\left(\mathrm{p}_{3}\right)$ and congruent and incongruent test ( $\left.\mathrm{p}_{4}\right)$ by Wilcoxon's Sign rank test 


\begin{tabular}{|c|c|c|c|c|c|c|c|c|c|}
\hline \multicolumn{10}{|c|}{ CONGRIENTSTROOPCARD } \\
\hline NED & BLUE & Gall & BROWN & PURLE & RED & BLUE & GREE & BROWI & PUR \\
\hline WUE & GREEI & BROWN & PURPIE & RED & BLUE & GREEN & BROWN & PURPLE & RED \\
\hline EII & BROWN & PURPLE & RED & BLUE & GREDY & BROWN & PURPLE & RED & BLUE \\
\hline OWN & PURPLE & RED & BUUE & GAFEI & BROWN & PURPLE & RED & BLUE & [aflF \\
\hline RPLE & RED & BUEE & Gones & BROWN & PURPLE & RED & $U E$ & GREE & BROWN \\
\hline ED & BUEE & Gatey & BROWN & PURPLE & RED & BLUE & 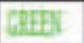 & BroWN & PURP. \\
\hline $\mathrm{dE}$ & 마패제 & BROWN & PURPLE & RED & BLUE & GREI) & BROWN & PURPLE & RED \\
\hline EEX & BROWN & PURPLE & RED & BLUE & GREAI & BROWN & PURPLE & RED & BLEE \\
\hline OOWN & PURPIE & RED & BLUE & RRES & BROWN & PURPLE & RED & BLUE & 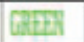 \\
\hline URPLE & RED & BUUE & CREEA & BROWN & PURPLE & RED & $=$ & GREEX & BRON \\
\hline \multicolumn{10}{|c|}{ INCONGRTENTSTROOPC.ARD } \\
\hline ED & Bllit & GREEV & BROWN & PURPLE & PEID & BLUE & GREEN & BROUX & PURPLE \\
\hline dE & GREEN & BROWN & Prowl & RED & BLUE & GREEN & DOWIII & PURPLE & RED \\
\hline EEV & BROWN & PURPLE & RED & BELE: & GREEV & BROWN & PURPLE & FED & BULE \\
\hline 10WN & PUNPFi & RED & BLUE & GREEV & Bnowil & PURPLE & RED & BLUE & GREEV \\
\hline PUPPLE & RED & Ellu & GREEV & BROWN & PURPLE & NED & BUUE & GREEN & BROWN \\
\hline EDD & BLUE & GREEN & BROWN & PURPL & RED & BUdE & GREEN & BROWIS & PURPLE \\
\hline ditit & GREEN & BROWN & PURPLE & RED & BLUE & GREEV & BROWN & PURPLE & 证) \\
\hline REEN & BROWN & FIRPLE & RED & BUUE & GREEV & BROUN & PURPLE & RED & BLUE \\
\hline ROWN & PURPIE & RED & Bulle & GREEV & BROWN & PURPLE & REIII) & BLUE & GREEV \\
\hline Wharl & RED & BLUE & GREEV & BROWN & PURPLE & RED & BLUE & GREEN & BaOWh \\
\hline
\end{tabular}

Figure 1: Congruent and Incongruent stroop test

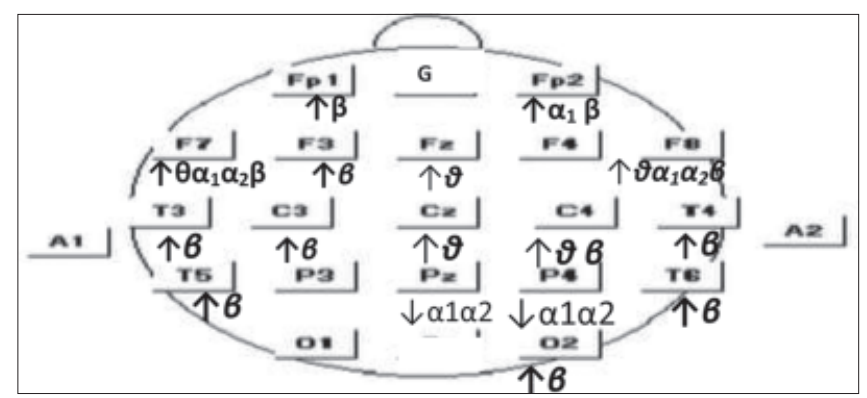

Figure 2: Baseline- congruent

network which is represented by production of theta waves and parietal lobe acting as posterior network which is represented by attenuation of alpha waves, there are still many controversies about how brain deals with selective attention. So, we conducted the study to observe what the changes in brain waves are during the selective attention.

So as to fulfil our objectives, our study was conducted on right handed $23.1 \pm 2.8$ yrs male undergraduate and postgraduate students because the literature on handedness and hemisphericity has shown handedness related lateralization. ${ }^{11}$ Also normal aging has shown changes in EEG with working memory process. ${ }^{12}$ Therefore to reduce the confounding factors, right handed with narrow range of age were taken. For the same purpose males were taken because literature has shown that men and women have

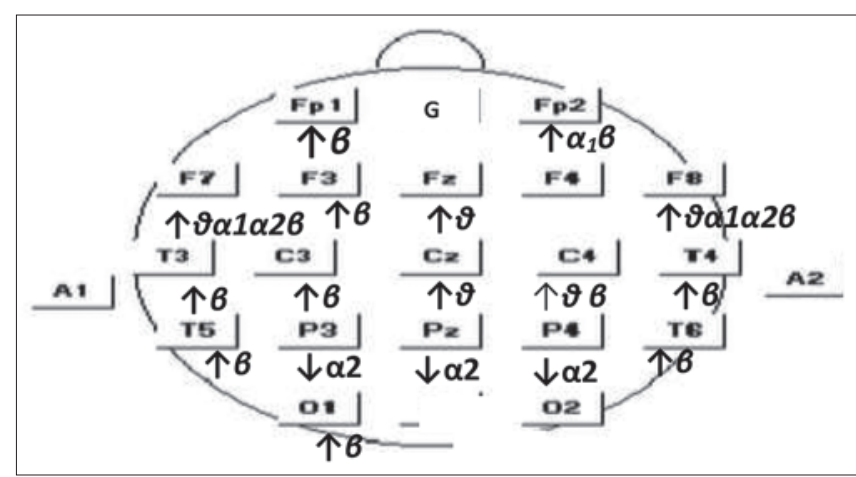

Figure 3: Baseline - incongruent

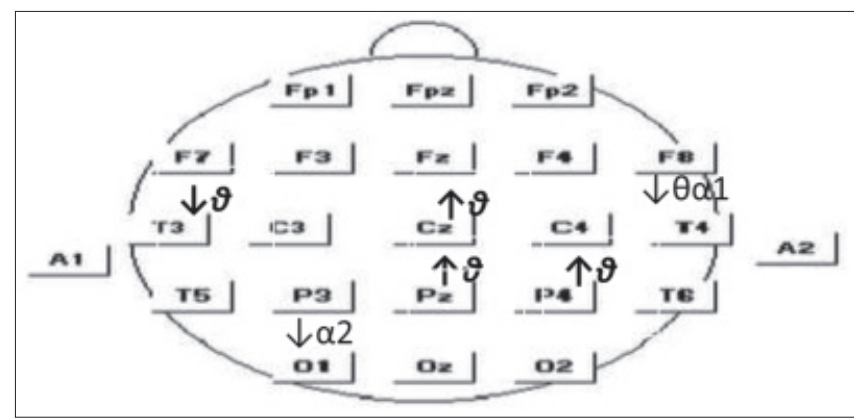

Figure 4: Congruent - incongruent

\begin{tabular}{llll}
\hline Brain area & Left & Midline & Right \\
\hline Frontal pole & Fp1 & Fpz (G) & Fp2 \\
Frontal & F3 & Fz & F4 \\
Inferior frontal & F7 & & F8 \\
Mid-temporal & T3 & & T4 \\
Posterior temporal & T5 & & T6 \\
Central & C3 & Cz & C4 \\
Parietal & P3 & Pz & P4 \\
Occipital & O1 & & O2 \\
\hline
\end{tabular}

different hemispheric lateralization, dominant hemispheres and rates of intrahemispheric transfer. ${ }^{13}$ Undergraduate and post graduate were selected because studies have shown that age, sex and education affects the performance during Stroop test. ${ }^{14}$ Also all the subjects having colour blindness, seizure disorder, using or abusing any drugs were excluded as these are shown to affect EEG. EEG was taken for ninety seconds while reading the cards.

EEG changes during normal reading and selective attention

Our study showed theta power increased at Fz, C4, Cz and $\mathrm{O} 1$ regions during both tests and increment was even more during incongruent stroop test which is also supported by other studies where they have shown increase in theta-band, mainly frontal midline theta (fm theta) with the performance of working memory, emotional states, and attention processes. They have also shown frontal midline theta increased in high load task than low load task. ${ }^{3,15}$ But in our study mid central 
and right central theta power also increased during incongruent stroop test. This suggests these areas may also be involved during selective attention.

Since increased alpha power (alpha synchronization) is regarded to represent the active inhibition of non-task relevant cortical areas and desynchronization reflects the gradual release of inhibition associated with the emergence of complex spreading activation processes ${ }^{5}$, the increase of alpha1 at F7 and F8 and Fp2 sites during both tests suggest the active inhibition of these areas during both tasks. ${ }^{4,15}$ The alpha1 power was more in congruent test and less in incongruent test in F8 region which might suggest it was released from active inhibition during incongruent test. The release from inhibition might be due to sudden exposure to unusual environment. This is also similar to other study which suggested increased alpha1 during easy task and decreased alpha power 1 with task difficulty. ${ }^{16}$ Along with alpha 1, power of theta also increased at F7 and F8 sites during both tests. Like alpha1, theta power (synchrony) in these sites also was significantly more in congruent test and less in incongruent test. For this, studies should be carried out on different theta bands to find out which one predominates in frontocentral region and which one in F8, F7 regions.

Alpha2 decreased at $\mathrm{P} 4$ and $\mathrm{Pz}$ sites during both tests compared to baseline. There was significant decrease in alpha 2 power at $\mathrm{P} 3$ region during incongruent test. Studies have suggested alpha suppression as involvement of that area. ${ }^{4}$ So we can say that during selective attention P3 is activated even more.

Studies have also shown that alpha 2 predominates over occipital or occipito-parietal junction and sensitive to visuospatial factors whereas alpha 1 component predominates over parietal and dorsolateral prefrontal cortex and highly sensitive to cognitive load that a task imposes. ${ }^{16}$ This is also consistent with our study as decrease in alpha 2 was shown at parietal region which may be due to visuospatial factors. Though alpha1 also decreased in $\mathrm{Pz}$ and $\mathrm{P} 4$ region, it was only in congruent test but there was no change in incongruent test. In contrary, though both alpha1 and alpha 2 increased in $\mathrm{F} 7$ and $\mathrm{F} 8$ region during both tests, only alpha1 significantly decreased at F8 sites suggesting alpha1 at right inferior temporal responds to more attention. But it needs more study.

Beta was found to be increased at almost all sites during both tests except Fz, Pz Cz, P4 and P3 regions. Significant differences in beta band were not found. One of the studies showed enhanced upper beta (25-30) Hz and suppressed mid beta (13-20) Hz activity mainly localized to posterior electrodes where mid beta suppression indicated increased attentional processes and memory demands. ${ }^{17}$ But we did not divide beta into upper and lower beta so we did not have the similar result. Other studies have also shown beta activity during different attention tests which was not found in our study. It may be due to difference in types of tests.

\section{CONCLUSION}

During more selective attention, the theta waves at $\mathrm{Fz} \mathrm{Cz}$ and C4 gets synchronized while desynchronizing alpha2 at parietal regions. The theta and alpha1 at inferior frontal regions were also desynchronized in incongruent test than congruent tests.

\section{Limitation and future scope}

We used the manual version of stroop cards, computerized version would have precisely recorded the point of selective attention. The decrease in theta and alpha 1 at inferior frontal regions should be studied even more.

\section{ACKNOWLEDGEMENT}

I acknowledge it to my collegues Uzwali Malla, Prakash Limbu, Dr. Kopila Agrawal, Dr.Nirmala Limbu, Dr. Dilip Thakur, Mrs Namrata Upadhyay and also to my supporting friends Mrs. Manju Lamsal and Mr Shyam sundar Chaudhary for their help and support.

\section{REFERENCES}

1. Christian G. Anxiety disorders Psychophysiological Aspects. In: Sadock BJ, Sadock VA eds. Kaplan and Sadock's synopsis of Psychiatry Behavioral Sciences/Clinical Psychiatry 9th ed. USA: Lippincott Williams and Wilkins, 2003, pp 595-642.

2. Suetsugi M, Mizuki Y, Ushijima I, Kobayashi T, Tsuchiya K, Aoki $\mathrm{T}$, et al. Appearance of frontal midline theta activity in patients with generalized anxiety disorder. Neuropsychobiology 2000;41:108-112.

3. Gevins A, Smith ME, McEvoy L and Yu D. High-resolution EEG mapping of cortical activation related to working memory: effects of task difficulty, type of processing, and practice. Cereb Cortex 1997;7:374-385.

4. Grabner RH, Fink A, Stipacek A, Neuper C and Neubauer AC. Intelligence and working memory systems: evidence of neural efficiency in alpha band ERD. Brain Res Cogn Brain Res 2004;20:212-225.

5. Klimesch W, Sauseng $P$ and Hanslmayr S. EEG alpha oscillations: the inhibition-timing hypothesis. Brain Res Rev 2007;53:63-88.

6. Pfurtscheller G, Stanc'ak A and Neuper C. Post-movement beta synchronization. A correlate of an idling motor area? Electroenceph. Clin. Neurophysiol 1996;98: 281-293.

7. Duffy $F H$, lyer VG and Surwillo WW. EEG in clinical diagnosis and its relationship to other neurological tests. In: Clinical electroencephalography and topographic brain mapping. Springer-Verlag;1989. p. 243-252. 
8. Awh E and Vogel EK. Interaction between attention and working memory. Neuroscience 2006;139:201-208.

9. HansImayr S, Pastotter B, Bauml KH, Gruber S, Wimber $\mathrm{M}$ and Klimesch $\mathrm{W}$. The electrophysiological dynamics of interference during the Stroop task. J Cogn Neurosci 2008;20:215-225.

10. MacLeod CM. Half a Century of Research on the Stroop Effect: An Integrative Review. Psychol Bull 1991;109:163-203.

11. Geschwind N and Galaburda AM. Cerebral Lateralization: Biological mechanism, association and pathology. Archi of Neurol 1985;42:634-654.

12. McEvoy LK, Pellouchoud E, Smith ME and Gevins A. Neurophysiological signals of working memory in normal aging. Brain Res Cogn Brain Res 2001;11:363-365.

13. Volf NV and Razumikova OM. Sex differences in EEG coherence during a verbal memory task in normal adults. Int J Psychophysiol 1999;34:113-122.

14. Van der Elst W, Van Boxtel MP, Van Breukelen GJ and Jolles J. The Stroop color-word test: influence of age, sex, and education; and normative data for a large sample across the adult age range. Assessment 2006;13:3:62-79.

15. Asada H, Fukuda $Y$, Tsunoda S, Yamaguchi M and Tonoike M. Frontal midline theta rhythms reflect alternative activation of prefrontal cortex and anterior cingulate cortex in humans. Neurosci Lett 1999; 15:274:29-32.

16. Genvis AS and Smith ME. Neurophysiological measures of working memory and individual differences in cognitive ability and cognitive style. Cereb cortex 2000;10:829-839.

17. Shahin AJ, Picton TW and Miller LM. Brain oscillations during semantic evaluation of speech. Brain Cogn 2009;70: 259-266.

\section{Authors Contribution:}

NG - Designing and planning of the research, performed the laboratory tests, analysed the data, reviewed the manuscript; BHP - Designing and planning of the research, analysed the data, and reviewed the manuscript; RK - Designing and planning of the research analysed the data, and reviewed the manuscript; PNS - Designing and planning of the research \& reviewed the manuscript; AD - Designing and planning of the research. 